\title{
Evaluation of the Cytotoxic Activity of Anthriscus nemorosa on Breast Cancer Cells
}

\author{
Haleh Forouhandeh ${ }^{1 \dagger}$, Mahtab Zarchini ${ }^{2 \dagger}$, Elham Safarzadeh³, Ommoleila Molavi', \\ Parina Asgharian ${ }^{5,6^{*}}$, Vahideh Tarhriz ${ }^{*}$
}

\begin{abstract}
'Molecular Medicine Research Center, Biomedicine Institute, Tabriz University of Medical Sciences, Tabriz, Iran.
2Student Research Committee, Tabriz University of Medical Sciences, Tabriz, Iran.

${ }^{3}$ Department of Microbiology \& Immunology, Faculty of Medicine, Ardabil University of Medical Sciences, Ardabil, Iran.

${ }^{4}$ Department of Pharmaceutical Biotechnology, Faculty of Pharmacy, Tabriz University of Medical Sciences, Tabriz, Iran.

${ }^{5}$ Department of Pharmacognosy, Faculty of Pharmacy, Tabriz University of Medical Sciences, Tabriz, Iran.

${ }^{6}$ Drug Applied Research Center, Tabriz University of Medical Sciences, Tabriz, Iran.

*Correspondence to: Parina Asgharian (E-mail: parina.asgharian@gmail.com), Vahideh Tarhriz (E-mail: t.tarhriz@yahoo.com)

TThese authors contributed equally to this work.

(Submitted: 03 March 2021 - Revised version received: 28 March 2021 - Accepted: 12 April 2021 - Published online: 26 August 2021)
\end{abstract}

\begin{abstract}
Objective The present study concerns the cytotoxic activity of A. nemorosa different extracts on breast cancer cells (MCF-7) and normal cell lines (HFFF).

Methods Different extracts of aerial parts of $A$. nemorosa were prepared using Soxhlet apparatus. The cytotoxicity of samples was assessed by MTT assay on breast cancer cells (MCF-7) and noncancerous cells (HFFF) with different concentrations of extracts in 24 and 48 hours. The most potent extract was fractioned and cytotoxic activity of fractions was considered, As well. A flow cytometry (annexin V/PI) assay has been used for detecting the mechanism of cell death in sample treated cell lines. Moreover, for clarifying volatile components of $n$-Hexane extract and its $80 \%$ and $100 \%$ VLC fractions were subjected to GC-MS apparatus.

Results Results indicated that n-Hexane extract and its $80 \%$ and $100 \%$ VLC fractions exhibited a significant $(P<0.001)$ inhibitory effect on the growth of the MCF-7 cell line compared to the control group. Meanwhile, flow cytometry analysis revealed that potent extract caused cell death through necrosis and $80 \%$ and $100 \%$ fractions showed different mechanisms (such as autophagy). The major compounds, which maybe were in charge of showing cytotoxic activity were non-terpenoids.

Conclusion This study provides the evidence that in vitro cytotoxic activity of n-Hexane extract and $80 \%$ and $100 \%$ VLC fractions of A. nemorosa inhibited the proliferation of breast cancer cells (MCF7) via a different mechanism.

Keywords Anthriscus nemorosa, cancer, GC-MS, cytotoxic, flow cytometry
\end{abstract}

\section{Graphical Abstract}

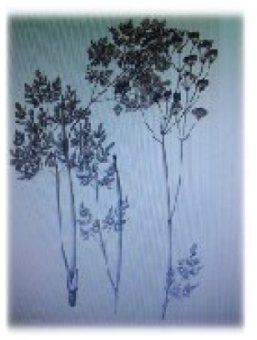

Anthriscus nemorosa

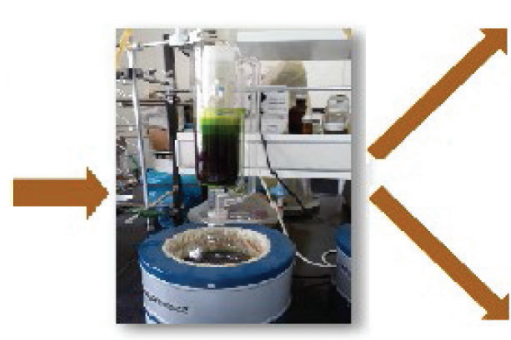

Extraction of aerial parts of A. nemorosa

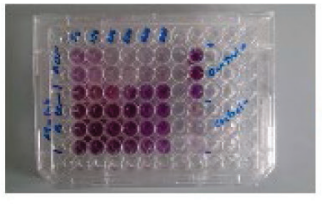

Cytotoxicity activity assay

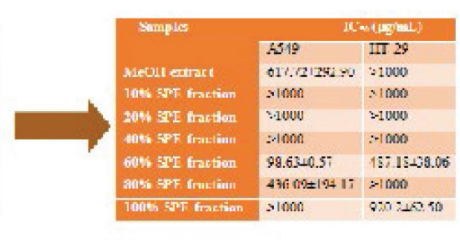

Analysis of data

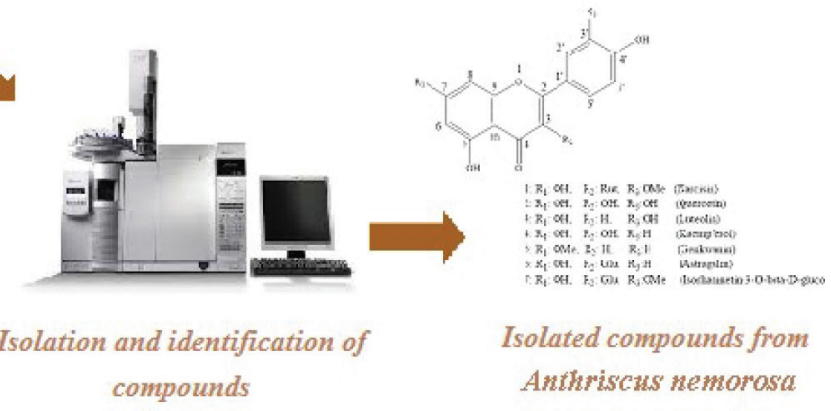

\section{Introduction}

Cancer is a disease that begins with the abnormal proliferation of cells in the body. All cancers have an uncontrolled growth pattern and a tendency to detach from the source and metastasize. Cancer mortality is on the rise and has become one of the leading causes of human mortality today. Breast cancer is one of the most common malignancies in Iranian women. ${ }^{1}$ Various factors such as old age of reproduction and lactation, radiation, smoking, alcohol, and many other factors increase the risk of developing this disease in women., ${ }^{2,3}$ Chemotherapy, surgery, radiotherapy, immunotherapy, gene therapy, hormone therapy, 
and cell therapy are some of the treatments available for this disease. ${ }^{4}$ Chemical drugs available on the market due to the side effects of the drug are less popular. In recent years, attention has been paid to drugs with natural sources and fewer side effects. ${ }^{5}$ Nature is an amazing source of suitable new drug compounds with great chemical diversity found in millions of plants, animal, marine, and microbial species. ${ }^{6,7}$ Plant compounds that have anti-cancer and anti-tumor properties are in the chemical groups of aldehydes, alkaloids, flavonoids, glycosides, terpenoids, and phenolic compounds. ${ }^{8-10}$ It is noteworthy that more than $60 \%$ of common anticancer drugs are now derived from natural sources, including plants, marine organisms, and microorganisms. ${ }^{11,12}$

Among the well-known medicinal plants, the genus Anthriscus from the Umbelliferae family has valuable compounds that are used in many cases, and has the following effects: anti-cough, diuretic, antipyretic, ${ }^{13}$ analgesic, ${ }^{14}$ antiviral, ${ }^{15}$ anti-asthma, ${ }^{16}$ insecticide, ${ }^{17}$ anti-inflammatory, ${ }^{18}$ an indirect inhibitor of cutaneous anaphylactic reactions, ${ }^{19}$ liver protector, ${ }^{20}$ a competitive inhibitor of CYP2C9 and CYP3A4 enzymes, ${ }^{21}$ reduction of skin pigmentation caused by UV light in guinea pigs. ${ }^{22}$ However, most studies show the anti-cancer effects of the compounds of this plant. ${ }^{13,18,23}$ Considering the increasing prevalence of breast cancer due to the importance of medicinal plants in cancer treatment and regarding less investigation on the cytotoxic effects of this plant on breast cancer, the present study aimed to evaluate the cytotoxic effects of the plant extract on the category of breast cancer cells.

\section{Materials and Methods}

\section{Preparation of Plant Samples}

Anthriscus nemorosa (MB) spreng (A. nemorosa) was collected in July 2016 from Ardabil province, Jafarabad Moghan region and was matched and identified with its herbarium specimen and identified as tbz.fph 1037 in the school herbarium. The sample was maintained in the faculty of pharmacy, Tabriz University of Medical Sciences, Tabriz, Iran.

\section{Preparation of Extracts}

The amount of $200 \mathrm{~g}$ of $A$. nemorosa plant powder ensuring weighing and loading was placed in a suitable cartridge paper in a 1-liter Soxhlet apparatus and extracted with n-Hexane (n-Hex), dichloromethane (DCM), and methanol (MeOH) solvents, respectively, for 72 hours. The soxhlet was placed on the balloon in the electric oven securing it with a clamp. Then, we added the desired solvents from the top of the Soxhlet chamber little by little until the solvent reaches half of the balloon. After adding the solvent, it was placed in the refrigerant on the soxhlet and opened the tube water. Then was turned on the electric stove and adjusted the temperature until the solvent boiled evenly inside the balloon. After the extraction, we turned off the device and discarded the plant pulp that did not contain the extract, and filtered the liquid extract inside the balloon with a funnel and filtered paper, and kept it in suitable containers.

\section{Fractionation}

VLC method was used to fractionate non-polar extracts. In this method, the extracts were first dried completely by rotary evaporator at $45^{\circ} \mathrm{C}$ and low air pressure. Fractionation was then performed using silica gel as the stationary phase and increasing percentages of ethyl acetate in hexane.

\section{Identification of Volatile Compounds in Non-polar Samples}

Gas chromatography-mass spectrometry (GC-MS) was used to identify the compounds in the n-Hex extract and its $80 \%$ and $100 \%$ fractions. Samples were injected into the device under the following conditions: Injection temperature: $270^{\circ} \mathrm{C}$, Column flow rate: $1.2 \mathrm{ml} / \mathrm{min}$, Split ratio: 1:10, Total flow: $18.4 \mathrm{ml} / \mathrm{min}$, and helium gas were used as carriers.

\section{Cell Lines Used in Experiments}

MCF-7 cell: This cell line includes breast cancer cells from a 69-year-old Caucasian woman from the Pasteur Institute of Iran.

HFFF cell: This cell line contains normal fibroblast cells that are from a newborn human and have been prepared by the Pasteur Institute of Iran.

\section{Cell Cultures}

The culture medium used is Roswell Park Memorial Institute (RPMI-1640), purchased from Sigma company in powder form. Cell lines were cultured in RPMI 1640 liquid culture medium containing $10 \% \mathrm{FBS}$ and $1 \%$ penicillin/streptomycin antibiotic. The cells were incubated in sterile flasks at $37^{\circ} \mathrm{C}$, $5 \% \mathrm{CO}_{2}$, and $95 \%$ moisture. Confluent cells (upon 70\%) are trypsinized and then subcultured at lower numbers in new culture flasks.

\section{Chemicals}

All solvents used in this research were purchased from Caledon Canada. All chemicals were analytical grade.

\section{Evaluation of Cytotoxicity of Extracts by MTT Method}

To perform this test, 200 microliters of cell suspension containing the appropriate number of cells (approximately 5000 cells) first was cultured uniformly in each of the plate wells and allowed the cells to adhere to the bottom of the plate and become stable. The plate is then incubated for 24 hours at $37^{\circ} \mathrm{C}, 95 \%$ humidity and $5 \%$ carbon dioxide until the cells reach the desired density. After this time, the cells are treated with different concentrations of n-Hex, DCM, and $\mathrm{MeOH}$ extracts. These concentrations have been determined through a previous pilot test. Then we moved the plates gently on the horizontal surface to homogenize and incubate them for 24 and 48 hours. The supernatant was then discarded and $150 \mu \mathrm{l}$ of the prepared MTT solution was added to each well, and the plates were transferred to a carbon dioxide incubator at $37^{\circ} \mathrm{C}$ for 4 hours in sterile aluminum foil. In this case, MTT (dimethylthiazole-2 and 5-diphenyltetrazolium bromide) is converted to insoluble purple formazan crystals by mitochondrial enzymes in living cells due to the rupture of the tetrazolium ring. After 4 hours, the contents of the wells are gently drained and $200 \mu$ lof DMSO is added to each well to dissolve the purple crystals of formazan. Finally, the light absorption of the obtained solution is read by a plate reader with a wavelength of $570 \mathrm{~nm}$.

\section{Detection by Flow Cytometry}

To perform the $2 \times 10^{5}$ cell test, 6 wells were added to each well from the plate. The plates were placed in a cell culture incubator for 24 hours. After this time and reaching the appropriate 
confluency of the cells, the cells were treated with concentrations equal to $\mathrm{IC}_{50}$ of $\mathrm{n}-\mathrm{Hex}$ extract and its fractions. For this purpose, the top culture medium of each well was emptied by Pasteur pipette and after washing with PBS, the cells were trypsinized from the bottom of the well and transferred to separate microtubes. The microtubes were then centrifuged and repeated after removing the medium on the cells and washing with PBS. After this step, disperse the cells in $100 \mu$ of diluted Annexin V Binding buffer and add $5 \mu$ of Annexin solution and PI dye to each microtubule. We incubated the contents in the dark for 30 minutes at room temperature. The microtubes are then centrifuged and the cells are dispersed in $200 \mu \mathrm{l}$ of Annexin V Binding Buffer. Finally, the absorbance of each sample at 488 and $617 \mathrm{~nm}$ is read by flow cytometry. All steps of this test are performed except incubation in ice.

\section{Statistical Analysis of Data}

The results obtained from UV absorption at a wavelength of $570 \mathrm{~nm}$ from the Plate reader were entered into GraphPad Prism 8.0.2 software and analyzed (curve fit) nonlinear regression to calculate $\mathrm{IC}_{50}$ (concentration of sample that inhibits $50 \%$ cell growth) was used. ANOVA analysis and Tukey post hoc test were used for comparison between groups. In all tests, the minimum level of significance was considered $P<0.05$.

\section{Results}

\section{Amounts of Extracts}

The results of weighing the extracts obtained from the extraction of $340 \mathrm{~g}$ of plant shoot powder by $\mathrm{n}-\mathrm{Hex}, \mathrm{DCM}$, and $\mathrm{MeOH}$ solvents are shown in Table 1. Because n-Hex extract showed a significant cell inhibitory effect compared to the other extracts and control group, $2 \mathrm{~g}$ of this extract were fractionated by the VLC method for further studies. The results of the weight of these fractions are also given in Table 1.

\section{Cytotoxicity Test Results}

\section{Evaluation of cytotoxic effects of plant samples by MTT method}

The $\mathrm{IC}_{50}$ values of the samples (the concentration of the drug that causes $50 \%$ of cell death) were calculated by GraphPad Prism 8.0.2 software. These numbers are based on the nonlinear regression diagram log (inhibitor) vs. Normalized responses-variable slope and drug concentration are calculated. Cells were treated with different concentrations of DCM, n-Hex, and MeOH extracts for 24 and 48 hours. N-Hex extract with the lowest amount of IC50 was the strongest fractionated extract and the relevant experiments were performed on the fractions. The $\mathrm{IC}_{50}$ values obtained are according to Table 2. To evaluate and determine the cytotoxic effects of n-Hex, DCM, and MeOH extracts, MCF-7 cells were treated with concentrations of $0,50,100,200,400,500,600$, and 800 $\mu \mathrm{g} / \mathrm{ml}$ of each sample. The results of the MTT test at 24 and 48 hours are shown in Figure 1. Due to the significant cytotoxicity of the n-Hex extract on MCF-7 cells compared to other extracts and the control group, in the next step, the fractions of n-Hex extract were tested by MTT. The results are available in Figure 2. Besides, for evaluation of the effect of cytotoxicity of $A$. nemorosa extracts and fractions on non-cancerous cells, an MTT assay was performed on a normal HFFF cell line. The results of $\mathrm{IC}_{50}$ from 24 and 48 hours treatment are as shown in Table 3.

\begin{tabular}{|c|c|c|c|c|c|c|}
\hline \multicolumn{2}{|c|}{$\mathrm{MeOH}$} & \multicolumn{2}{|c|}{$D C M$} & \multicolumn{2}{|c|}{$n-H e x$} & Extract \\
\hline \multicolumn{2}{|c|}{18.96} & \multicolumn{2}{|c|}{5.34} & \multicolumn{2}{|c|}{6.73} & $\begin{array}{l}\text { Weight of plant extract ( } \mathrm{g} / 100 \mathrm{~g} \text { of } \\
\text { extract) }\end{array}$ \\
\hline $100 \%$ & $80 \%$ & $60 \%$ & $40 \%$ & $20 \%$ & $10 \%$ & Fractions \\
\hline 7.48 & 15.25 & 9.65 & 13.80 & 14.43 & 7.35 & $\begin{array}{l}\text { Weight of } \mathrm{n} \text {-Hexane extract fraction } \\
\text { (g/100 g of extract) }\end{array}$ \\
\hline
\end{tabular}

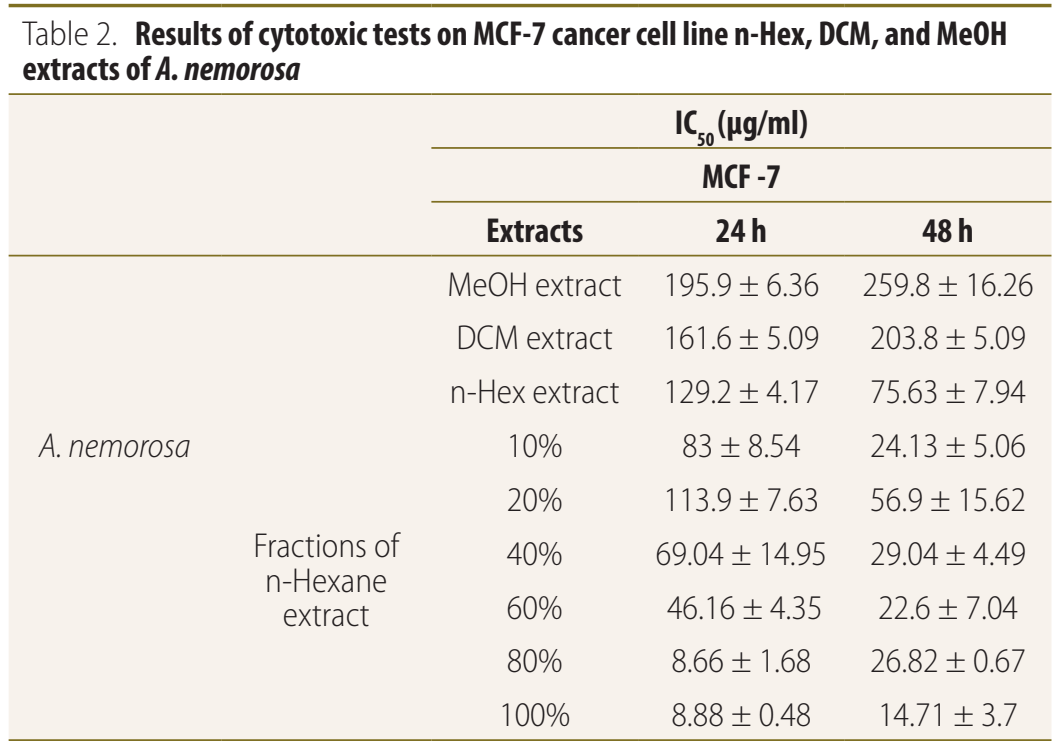



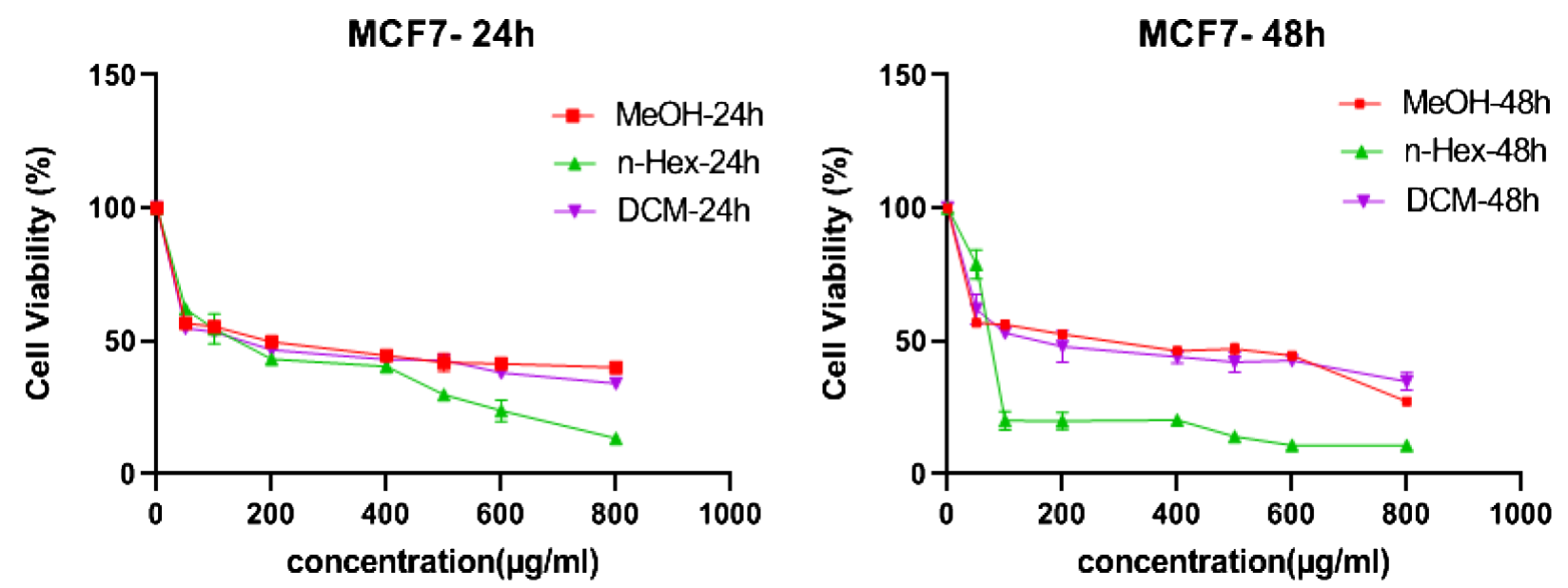

Fig. 1 Viability of MCF-7 cancer cells after exposure to increasing concentrations of n-Hex, DCM, and MeOH extracts of A. nemorosa after 24 and 48 hours of incubation.
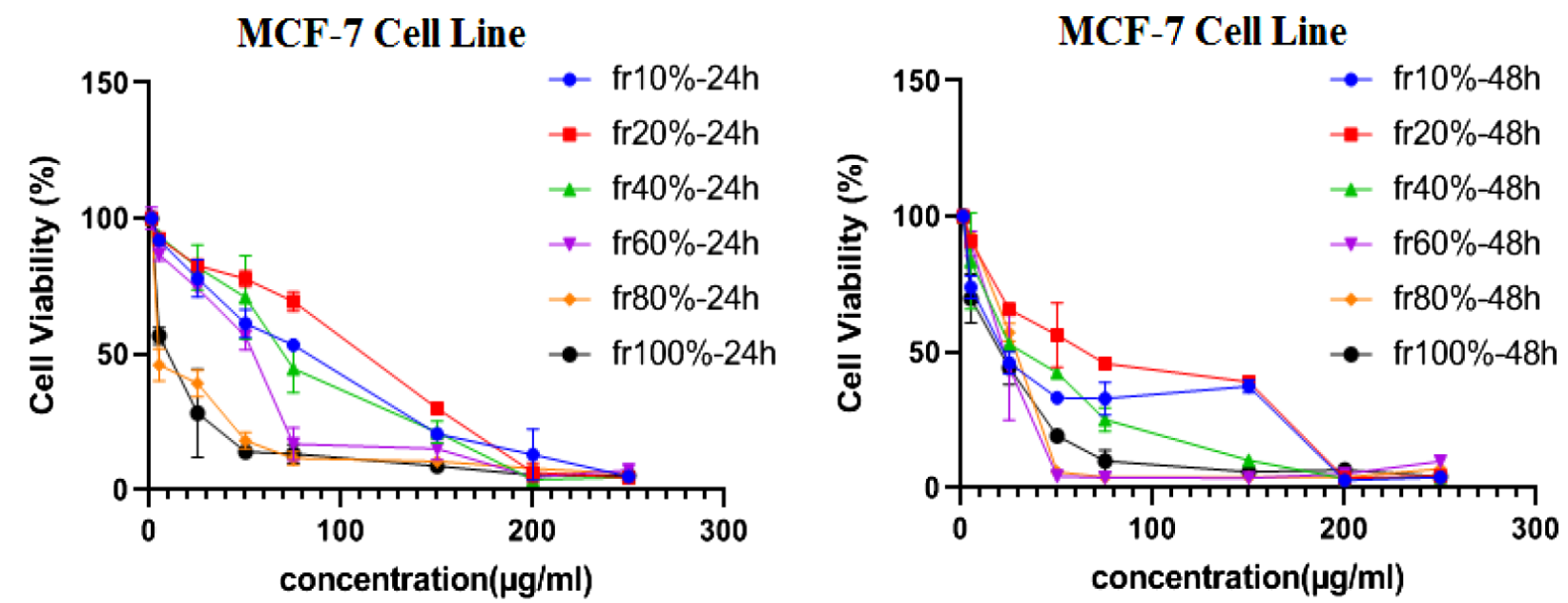

Fig. 2 Viability of MCF-7 cells treated with different concentrations of $A$. nemorosa n-Hex extract fractions using MTT method in 24 and 48 hours of incubation.

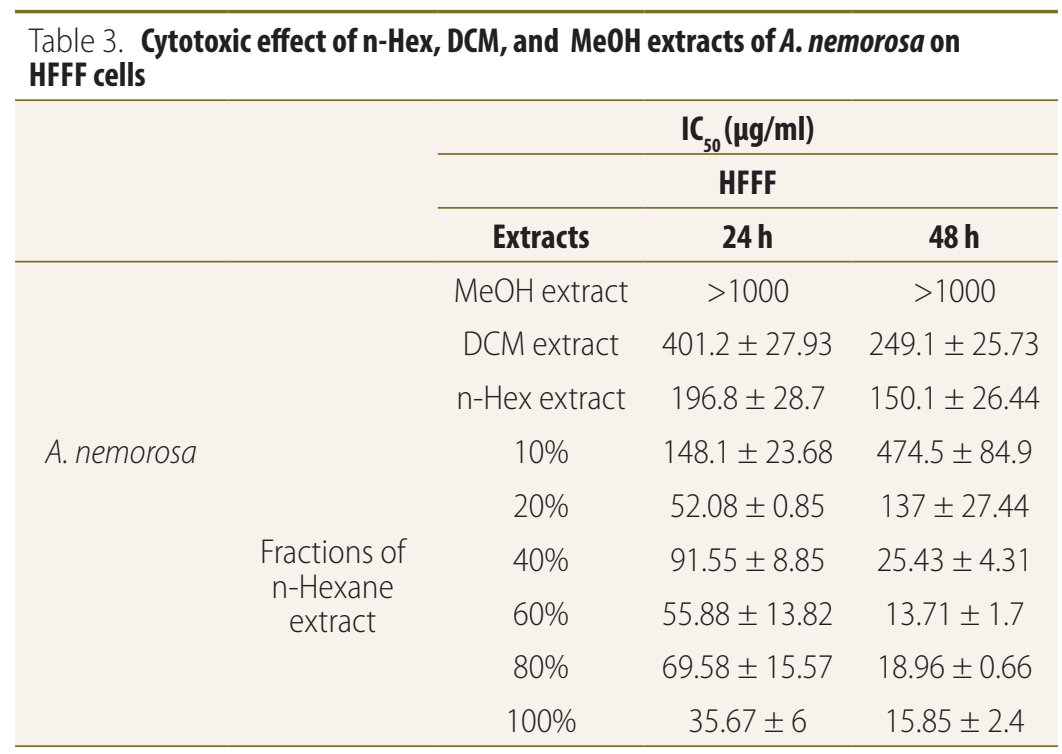

\section{Significant comparison of the effect of different samples with controls}

Two Way ANOVA test and Tukey post hoc test were used to compare the cytotoxic effects of different plant samples at 24 and 48 hours. In statistical tests, the significance level is defined as ns $(P>0.05),{ }^{*}(P<0.05),{ }^{* *}(P, 0.01),{ }^{* * *}(P<0.001)$. The viability of MCF-7 and HFFF cells after treatment with n-Hex, DCM, and $\mathrm{MeOH}$ extracts after 24 and 48 hours of incubation is shown in Figures 3 and 4, respectively. Statistical analysis of 


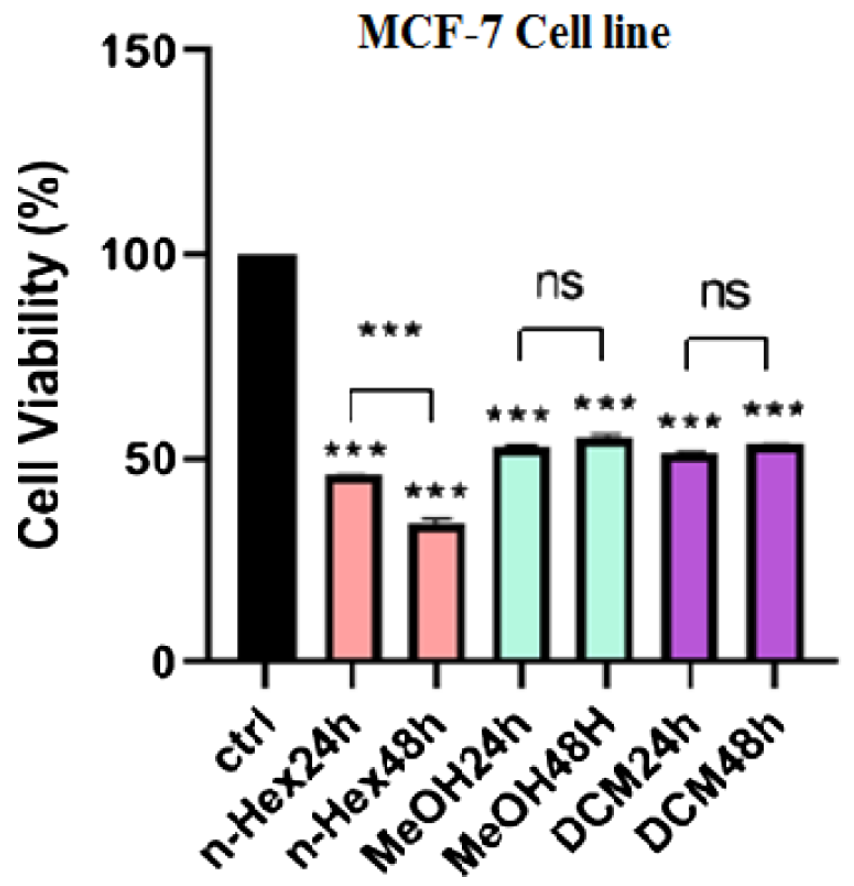

Fig. 3 Statistical comparison of viability of MCF-7 cells treated with n-Hex, DCM, and MeOH extracts of A. nemorosa compared to the control group, using MTT method.

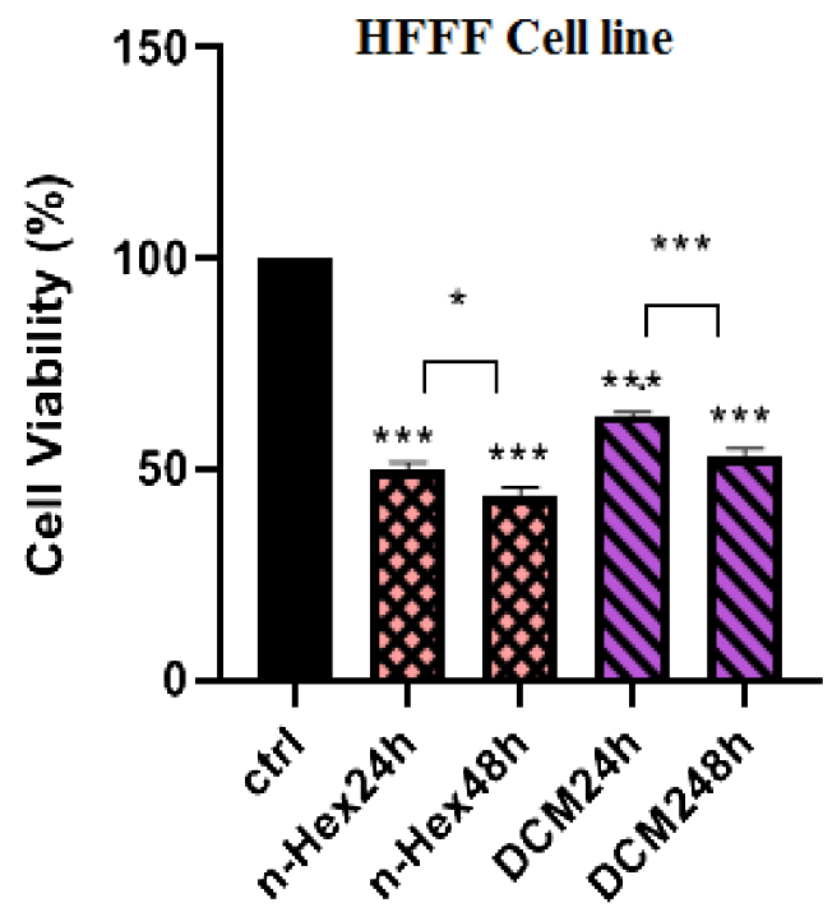

Fig. 4 Statistical comparison of viability of HFFF cells treated with $\mathrm{n}$-Hex and DCM extracts of A. nemorosa compared to the control group, using MTT method.

ANOVA and Tukey post hoc test showed that the relevant extracts at both incubation times ( 24 and 48 hours) were significantly different from the DMSO control group. The results of the statistical comparison of n-Hex fractions at 24 and 48 hours are also shown in Figure 5. According to Figure 6, the viability of MCF-7 cells in the presence of DCM and $\mathrm{MeOH}$ extracts in 24 hours and n-Hex and $\mathrm{MeOH}$ extracts in 48 hours relative to the cell HFFF levels are significantly reduced.

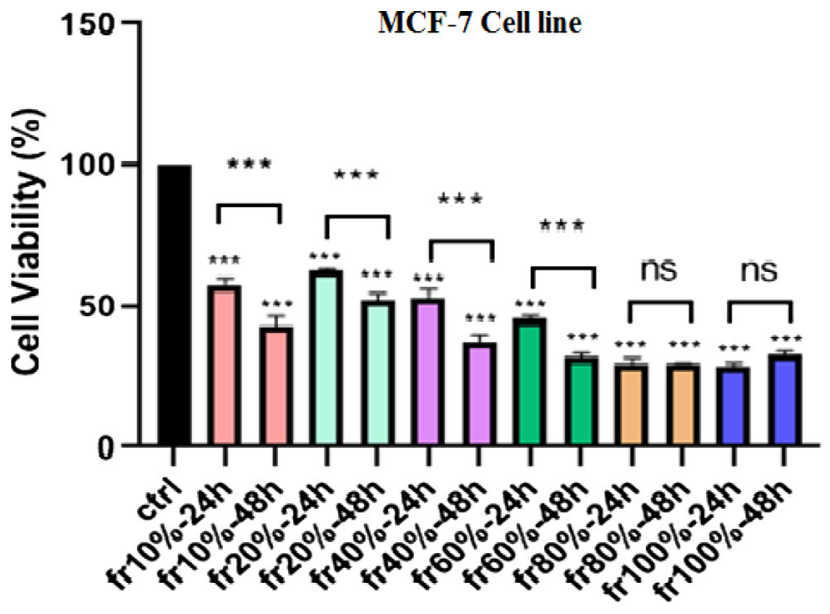

Fig. 5 Statistical comparison of viability of MCF-7 cells treated with $\mathrm{n}$-Hex extracts fractions compared to the control group, using MTT method.

\section{Flow cytometry test results on MCF-7 cells}

In this test, n-Hex extract and $60 \%, 80 \%$, and $100 \%$ fractions were incubated with cancer cell lines for 24 hours at $\mathrm{IC}_{50}$ concentration. Flow cytometry was performed to determine the extent of apoptosis. The test histogram view is shown in Figure 7. The amount of apoptotic and necrotic cells can be seen in the diagram Figure 7.

Identification of compounds in n-Hex extract and its $80 \%$ and $100 \%$ fractions via GC-MS

Data on compounds identified in n-Hex extract and its $80 \%$ and $100 \%$ fractions obtained by injection into GC-MS are available in the following Tables 4, 5, and 6. According to obtain results the major components are belong to non-terpenoid compounds.

\section{Discussion}

Global cancer status around the world using GLOBOCAN 2018 estimates, the incidence and mortality of cancer by the International Agency for Research on Cancer, with a focus on geographical diversity in 20 regions of the world is estimated that in 2018 about 18.1 million new cancers. ${ }^{24}$ Breast cancer has been diagnosed as the most common cancer among women. Diagnosis of cancer and the leading cause of death varies from country to country depending on the rate of economic development and lifestyle-related factors. ${ }^{25}$ In a review, medicinal plants in Iran with anti-cancer effects in different cell lines have been studied. In most studies, phenolic compounds and alkaloids have anticancer effects on various cancers. Plants and their active compounds have anti-cancer effects by eliminating free radicals and antioxidant effects, stopping the cell cycle, inducing apoptosis, and inhibiting angiogenesis. Therefore, extracts and active compounds of medicinal plants can greatly help researchers and pharmacists in developing new anticancer drugs. ${ }^{26}$

In the present study, the cytotoxic effects of n-Hex, DCM, and $\mathrm{MeOH}$ extracts of $A$. nemorosa on MCF-7 and HFFF cell lines were investigated for the first time. For this purpose, at the beginning of the work, cytotoxicity and $\mathrm{IC}_{50}$ values obtained from the treatment of these cells with different concentrations of extracts were investigated. The results showed 
After 24 hours

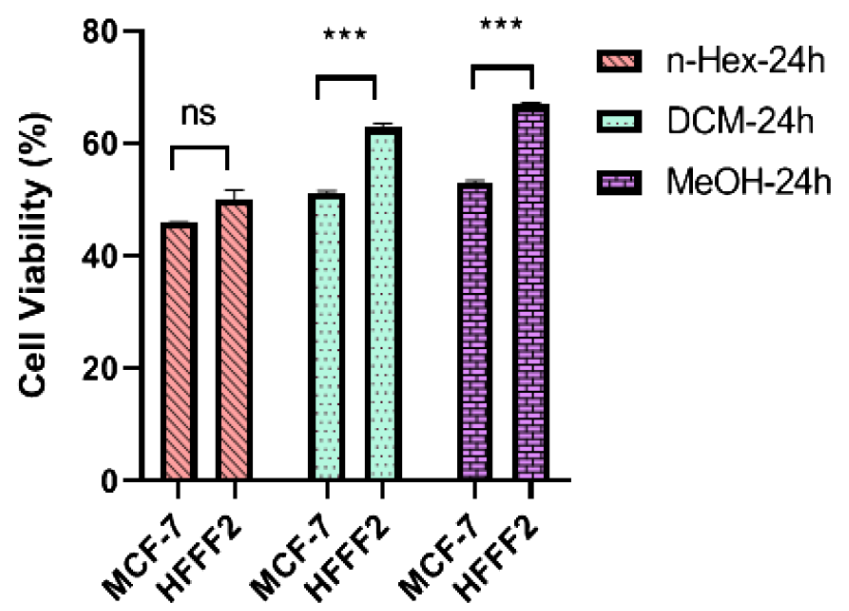

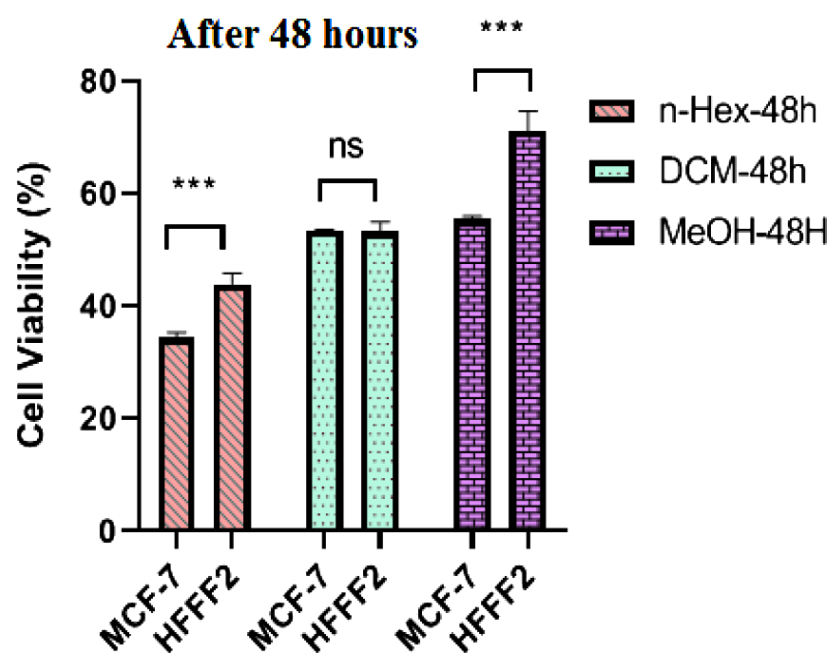

Fig. 6 MCF-7 cancer cell viability due to exposure to n-Hex, DCM, and MeOH extracts of $A$. nemorosa compared to normal HFFF cells in 24 and 48 hours of incubation.

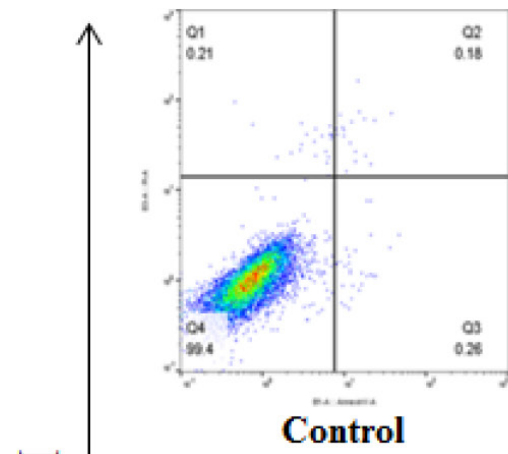

$\bar{\Sigma}$

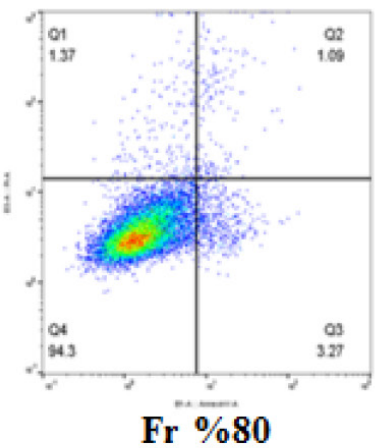

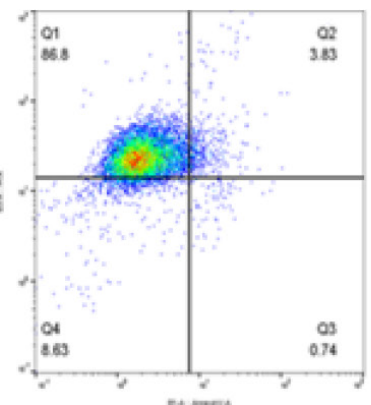

n-Hex extract

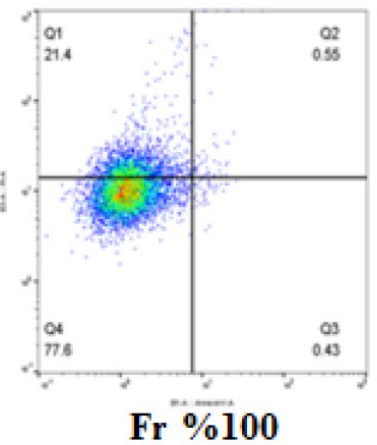

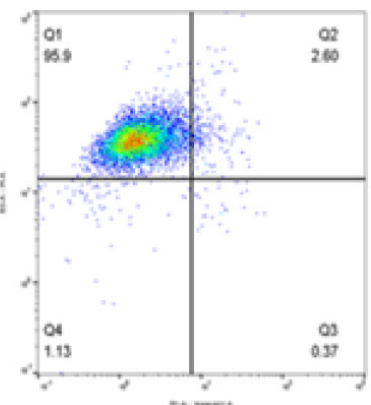

Fr \%60

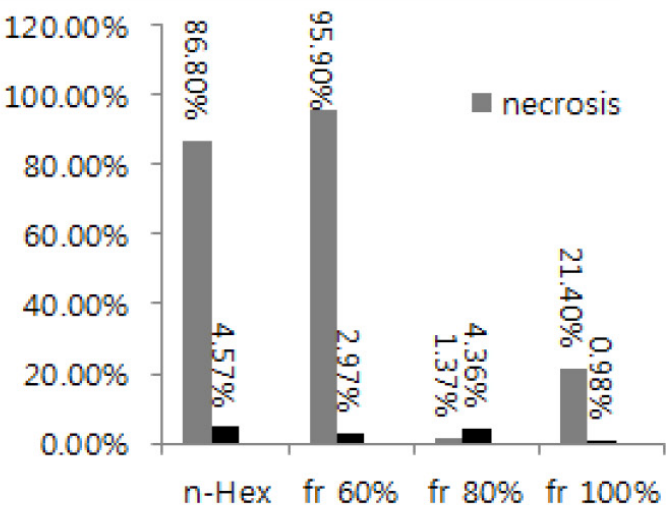

Annexin

Fig. 7 Flow cytometric test of $n$-Hex extract and some of its fractions on MCF-7 cells and comparison of apoptotic and necrotic cells in MCF-7 cell line.

that n-Hex extract had significantly $(P<0.001)$ more cytotoxicity on MCF-7 cancer cells in 24 and 48 hours treatment compared to DCM, MeOH extracts and DMSO control. In addition, according to the findings of this study, the cytotoxic effect of n-Hex extract on MCF-7 cells is dose-dependent and time-dependent with a $P$-value $<0.001$. The percentages of apoptosis and necrosis in n-Hex extract are $4.57 \%$ and $86.8 \%$, respectively. Then, n-Hex extract was selected as the most potent extract and fractionation was performed by the VLC method.

The $80 \%$ and $100 \%$ fractions of $n-H e x$ extract showed the highest effect of cytotoxicity on the tested cell line compared to other fractions. These fractions with a $P$-value $<0.001$ showed more cytotoxicity than control (DMSO) at both incubation times ( 24 and 48 hours). The effect of $n$-Hex extract fractions is dose-dependent and all fractions except $80 \%$ and $100 \%$ fractions with $P$-value $<0.001$ are time-dependent. $80 \%$ and $100 \%$ fractions did not show significant differences in 24 and 48 hours of treatment. The percentages of apoptosis and necrosis in the $60 \%$ fraction are $2.97 \%$ and $95.9 \%$, in the $80 \%$ fraction $4.36 \%$ and $1.37 \%$, and in the $100 \%$ fraction $0.98 \%$ and $21.4 \%$, respectively. The two fractions $80 \%$ and $100 \%$ act in a way other than apoptosis and necrosis, which can probably be attributed to other methods such as autophagy. Of course, it is 


\begin{tabular}{|c|c|c|c|c|c|}
\hline No. & Molecular formula & KI & Amount (Percentage) & Retention time (Minutes) & Compounds \\
\hline 1 & $\mathrm{C}_{10} \mathrm{H}_{16} \mathrm{O}$ & 1148.77 & 1.10 & 16.450 & (S)-cis-Verbenol \\
\hline 2 & $\mathrm{C}_{12} \mathrm{H}_{26}$ & 1198.74 & 1.91 & 18.000 & Dodecane \\
\hline 3 & $\mathrm{C}_{12} \mathrm{H}_{16} \mathrm{O}_{2}$ & 1247.81 & 2.24 & 19.475 & Chrysanthenyl acetate \\
\hline 4 & $\mathrm{C}_{14} \mathrm{H}_{3} \mathrm{O}$ & 1398.74 & 9.97 & 23.867 & Tetradecane \\
\hline 5 & $\mathrm{C}_{15} \mathrm{H}_{24}$ & 1515.81 & 3.17 & 25.192 & (Z)-.beta.-Farnesene \\
\hline 6 & $\mathrm{C}_{12} \mathrm{H}_{26} \mathrm{O}$ & 1538.27 & 3.57 & 25.442 & 1-Dodecanol \\
\hline 7 & $\mathrm{C}_{5} \mathrm{H}_{8} \mathrm{O}_{2}$ & 1619.13 & 0.97 & 26.342 & (E)-2-methylcrotonic acid \\
\hline 8 & $\mathrm{C}_{14} \mathrm{H}_{30} \mathrm{O}$ & 1659.94 & 0.98 & 30.625 & 1-Tetradecanol \\
\hline 9 & $\mathrm{C}_{14} \mathrm{H}_{30} \mathrm{O}_{2}$ & 1698.8 & 2.77 & 31.567 & Ethylene glycol monododecyl ether \\
\hline 10 & $\mathrm{C}_{18} \mathrm{H}_{38}$ & 1798.08 & 1.39 & 33.850 & Octadecane \\
\hline 11 & $\mathrm{C}_{20} \mathrm{H}_{40} \mathrm{O}$ & 1836.48 & 2.59 & 34.692 & Trans-phytol \\
\hline 12 & $\mathrm{C}_{16} \mathrm{H}_{32} \mathrm{O}_{2}$ & 1940.57 & 6.65 & 36.925 & Palmitic acid \\
\hline 13 & $\mathrm{C}_{20} \mathrm{H}_{42} \mathrm{O}_{2}$ & 1969.03 & 2.03 & 37.517 & 2-Octadecoxyethanol \\
\hline 14 & $\mathrm{C}_{18} \mathrm{H}_{36} \mathrm{O}_{2}$ & 1975.04 & 0.85 & 37.642 & Hexadecanoic acid, ethyl ester \\
\hline 15 & $\mathrm{C}_{19} \mathrm{H}_{4} \mathrm{O}$ & 1997.5 & 1.02 & 38.108 & n-Nonadecane \\
\hline 16 & $\mathrm{C}_{20} \mathrm{H}_{40} \mathrm{O}$ & 2097 & 1.76 & 40.158 & Phytol \\
\hline 17 & $\mathrm{C}_{20} \mathrm{H}_{36} \mathrm{O}_{2}$ & 2155 & 1.02 & 40.917 & Linoleic acid, ethyl ester \\
\hline 18 & $\mathrm{C}_{23} \mathrm{H}_{46} \mathrm{O}_{2}$ & 2502 & 1.52 & 47.417 & Docosanoic acid, methyl ester \\
\hline 19 & $\mathrm{C}_{25} \mathrm{H}_{50} \mathrm{O}_{2}$ & 2712 & 3.10 & 50.808 & Methyl tetracosanoate \\
\hline 20 & $\mathrm{C}_{31} \mathrm{H}_{64}$ & 3100 & 6.02 & 59.517 & n-Hentriacontane \\
\hline 21 & $\mathrm{C}_{22} \mathrm{H}_{24} \mathrm{O}_{7}$ & 3225 & 2.77 & 60.417 & Deoxypodorhizon \\
\hline 22 & $\mathrm{C}_{22} \mathrm{H}_{22} \mathrm{O}_{7}$ & 3267 & 1.99 & 61.608 & Desoxypodopyllotoxin \\
\hline \multirow[t]{4}{*}{23} & $\mathrm{C}_{18} \mathrm{H}_{34} \mathrm{O}$ & - & 2.32 & 40.317 & 9,12-Octadecadien-1-ol \\
\hline & & & & & 61.71 Identified \\
\hline & & & & & $35.7 \quad$ Non-terpenoid \\
\hline & & & & & 26.01 Terpenoid \\
\hline
\end{tabular}

\begin{tabular}{|c|c|c|c|c|c|}
\hline & \multicolumn{5}{|c|}{ Characteristics of volatile compounds identified in the $80 \%$ fraction of $n$-Hex extract of $A$. nemorosa } \\
\hline $\begin{array}{l}\text { Table } \\
\text { No. }\end{array}$ & Molecular formula & KI & Amount (Percentage) & Retention time (Minutes) & Compounds \\
\hline 1 & $\mathrm{C}_{13} \mathrm{H}_{28} \mathrm{O}$ & 1456.2 & 11.26 & 25.425 & 1-Tridecanol \\
\hline 2 & $\mathrm{C}_{7} \mathrm{H}_{12} \mathrm{O}_{2}$ & 1488.51 & 2.04 & 26.3 & $\begin{array}{l}\text { Cyclopropanecarboxylic, 1-methyl-, } \\
\text { ethyl ester }\end{array}$ \\
\hline 3 & $\mathrm{C}_{14} \mathrm{H}_{30} \mathrm{O}$ & 1659.26 & 2.54 & 30.608 & n-Tetradecanol \\
\hline 4 & $\mathrm{C}_{14} \mathrm{H}_{30} \mathrm{O}_{2}$ & 1698.51 & 25.22 & 31.558 & Ethanol, 2-(dodecyloxy)- \\
\hline 5 & $\mathrm{C}_{20} \mathrm{H}_{38}$ & 1835.71 & 1.26 & 34.675 & Neophytadiene \\
\hline 6 & $\mathrm{C}_{16} \mathrm{H}_{32} \mathrm{O}_{2}$ & 1937.35 & 9.98 & 36.858 & n-Hexadecanoic acid \\
\hline 7 & $\mathrm{C}_{20} \mathrm{H}_{40} \mathrm{O}$ & 2097 & 1.78 & 40.142 & Phytol \\
\hline 8 & $\mathrm{C}_{18} \mathrm{H}_{32} \mathrm{O}_{2}$ & 2109 & 1.34 & 40.258 & 9,12-Octadecadienoic acid (Z,Z)- \\
\hline 9 & $\mathrm{C}_{22} \mathrm{H}_{24} \mathrm{O}_{7}$ & 3225 & 4.96 & 60.392 & Deoxypodorhizon \\
\hline 10 & $\mathrm{C}_{22} \mathrm{H}_{22} \mathrm{O}_{7}$ & 3267 & 4.22 & 61.558 & Desoxypodophyllotoxin \\
\hline 11 & $\mathrm{C}_{29} \mathrm{H}_{50} \mathrm{O}$ & 3351 & 3.64 & 67.45 & gamma.-sitosterol \\
\hline \multirow[t]{4}{*}{12} & $\mathrm{C}_{29} \mathrm{H}_{48} \mathrm{O}$ & - & 7.8 & 65.117 & trans-stigmasta-5,22-dien-3.beta.-ol \\
\hline & & & & & 72.04 Identified \\
\hline & & & & & 51.38 Non-terpenoid \\
\hline & & & & & 22.66 Terpenoid \\
\hline
\end{tabular}




\begin{tabular}{|c|c|c|c|c|c|}
\hline No. & Molecular formula & KI & Amount (Percentage) & Retention time (Minutes) & Compounds \\
\hline 1 & $\mathrm{C}_{13} \mathrm{H}_{28} \mathrm{O}$ & 1456.2 & 0.67 & 25.425 & 1-Tridecanol \\
\hline 2 & $\mathrm{C}_{5} \mathrm{H}_{8} \mathrm{O}_{2}$ & 1491.32 & 3.68 & 26.367 & $\begin{array}{l}\text { (E)- 2-methylcrotonic } \\
\text { acid }\end{array}$ \\
\hline 3 & $\mathrm{C}_{12} \mathrm{H}_{24} \mathrm{O}_{2}$ & 1539.28 & 0.68 & 27.617 & Lauric acid \\
\hline 4 & $\mathrm{C}_{14} \mathrm{H}_{30} \mathrm{O}_{2}$ & 1698.1 & 1.90 & 31.550 & 2-Dodecyloxyethanol \\
\hline 5 & $\mathrm{C}_{14} \mathrm{H}_{28} \mathrm{O}_{2}$ & 1736.81 & 0.77 & 32.442 & Myristic acid \\
\hline 6 & $\mathrm{C}_{20} \mathrm{H}_{38}$ & 1835.71 & 0.61 & 34.675 & Neophytadiene \\
\hline 7 & $\mathrm{C}_{16} \mathrm{H}_{32} \mathrm{O}_{2}$ & 1940.19 & 13.22 & 36.917 & Palmitic acid \\
\hline 8 & $\mathrm{C}_{14} \mathrm{H}_{30} \mathrm{O}_{2}$ & 1968.6 & 12 & 37.508 & Laureth-1 \\
\hline 9 & $\mathrm{C}_{19} \mathrm{H}_{32} \mathrm{O}_{2}$ & 2092 & 7.35 & 40.400 & $\begin{array}{l}\text { Linolenic acid, methyl } \\
\text { ester }\end{array}$ \\
\hline 10 & $\mathrm{C}_{19} \mathrm{H}_{40} \mathrm{O}$ & 2176 & 9.58 & 42.708 & 2-nonadecanol \\
\hline 11 & $\mathrm{C}_{22} \mathrm{H}_{24} \mathrm{O}_{7}$ & 3225 & 3.06 & 60.383 & Deoxypodorhizon \\
\hline 12 & $\mathrm{C}_{22} \mathrm{H}_{22} \mathrm{O}_{7}$ & 3276 & 4.45 & 61.575 & Desoxypodophyllotoxin \\
\hline \multirow[t]{4}{*}{13} & \multirow[t]{4}{*}{$\mathrm{C}_{18} \mathrm{H}_{34} \mathrm{O}$} & \multirow[t]{4}{*}{-} & \multirow[t]{4}{*}{5.89} & \multirow[t]{4}{*}{40.317} & 9,12-Octadecadien-1-ol \\
\hline & & & & & 63.86 Identified \\
\hline & & & & & 55.74 Non-terpenoid \\
\hline & & & & & 8.12 Terpenoid \\
\hline
\end{tabular}

worth mentioning that the fraction has a necrosis mechanism $100 \%$ relative to itself. Furthermore, flow cytometry results showed that in the $80 \%$ fraction, the mechanism of cytotoxicity was other than necrosis and apoptosis. The results of statistical analysis showed that the effect of cytotoxicity depends on the concentration of extracts and fractions as, with increasing the concentration of plant samples, the viability of cells decreases.

The viability of cells after treatment with $\mathrm{MeOH}$ and DCM extracts does not depend on the exposure time of cells in the MCF-7 cell line. Various studies on the anticancer effects of different species of the genus Anthriscus have proven the cytotoxic properties of these plants in the treatment of cancer, and several anti-cancer compounds of this genus have been purified. The essential oil derived from plant $A$. Caucalis was tested on HepG 2 and MCF-7 cell lines by MTT method and reported $\mathrm{IC}_{50}=67.50 \mu \mathrm{g} / \mathrm{mL}$ and $\mathrm{IC}_{50}=55.83 \mu \mathrm{g} / \mathrm{mL}$, respectively, which was also significant in terms of dose and time. Its pronounced anti-cancer effect can be attributed to the pronounced presence of two beta-compounds ( $\beta$-Bisabolene) and (Z, E)- $\alpha$ Farnesene. ${ }^{27}$ Although the mechanism of extracts and fractions cytotoxicity of $A$. nemorosa which we discussed was necrosis or other than necrosis and apoptosis, in another study an active compound with antitumor activity was isolated from the root of A. sylvestris and structural studies showed that this compound was deoxy podophyllotoxin (DPPT) and its biological activity in human cervical cancer cells (HeLa) was examined. Flow cytometric analysis showed that DPPT stops the cell cycle in the G2/M phase before apoptosis, and DPPT functional mechanisms include inhibition of tubulin polymerization and activation of caspases 3 and $7 .{ }^{28}$ Another study in A. sylvestris showed that deoxypodophyllotoxin, as the most important constituent of this plant, is converted to epipodophyllotoxin, which is the main substance for the semi-synthesis of cytostatic agents of etoposide and teniposide. ${ }^{29}$

Autophagy plays an important role in the development of this type of cancer, although the exact underlying mechanisms are unknown. The data confirmed that anthracin causes apoptosis in 2 breast cancer cell lines, MCF-7 (estrogen receptor-positive) and MDA-MB-231 (estrogen receptor, progesterone receptor, and Her2 / Neu negative receptor). Anthracin reduces the phosphorylated levels of Akt and mTORC1 and subsequently inhibits cell growth. ${ }^{30}$ Interestingly, prevention of autophagy by a drug inhibitor or genetic deletion of ULK1 and Atg13 accelerates the process of anthracin-induced apoptosis, and autophagy has protective effects on the cell..$^{30}$ Overall, our results suggest that anthracin is an inhibitor of mTOR and that a combination of an autophagy inhibitor and anthracin may serve as a promising new strategy for the treatment of breast cancer cells.

The predominant escape composition of this extract by phytochemistry by GC-MS is non-terpenoid and these substances are probably responsible for the toxic effects of cancer cells. The most common ingredient in this extract is palmitic acid. In a study on marine algal extract, palmitic acid was identified as a selective anti-cancer compound. This compound induces apoptosis in human leukemia cancer cell lines and has shown an anti-cancer effect on mice in vitro. ${ }^{31}$ The second major component of $\mathrm{n}$-Hex extract is $\mathrm{N}$-hentriacontane, which is an antioxidant and cytotoxic compound against cancer cells. $^{32}$ In the $80 \%$ fraction, tri-decanol and hexadecanoic acid are the main compounds. In previous studies, the cytotoxicity of various alkanes has been investigated, which includes a wide range, and Tetradecane has a weaker cytotoxic effect than other alkanes. ${ }^{33}$ Fukuzawa et al., (2008), showed the biologically active compounds, which were isolated from Ganoderma 
lucidum spores and studied to inhibit the growth of human promyelocytic leukemia cells (HL60) by several different types of long-chain fatty acids, including hexadecanoic acid. They indicated that Hexadecanoic acid can inhibit the growth of this cell line with $\mathrm{IC}_{50}=132 \pm 25 \mu \mathrm{g} / \mathrm{ml} .^{34}$ In the $100 \%$ fraction, it is the major non-terpenoid compound and the most common compound is palmitinic acid. Desoxypodophyllotoxin is an important compound among the extracts and fractions. Podophyllotoxin, which has a significant anti-cancer effect, ${ }^{35}$ has been obtained from other genera of the same family as this plant. Podophyllotoxin is one of the most popular plant lignans that has been used as the main ingredient in the preparation of potent anticancer drugs such as etoposide and teniposide. ${ }^{36}$

\section{Conclusion}

In general, it can be concluded that the n-Hex extract of A. nemorosa and its $60 \%, 80 \%$, and $100 \%$ fractions showed the greatest effects of inhibiting cancer cell growth on MCF-7 cancer cell lines. It is noteworthy that the mechanism of action of n-Hex extract and its $60 \%$ fraction on MCF-7 is mainly necrosis and $80 \%$ and $100 \%$ fractions on MCF-7 are in a path other than apoptosis and necrosis. According to the obtained results, the anti-cell growth effects of the shoots of these plants can be attributed to the n-Hex extract, which is probably due to the presence of non-terpenoid compounds. Extensive and detailed phytochemical studies can determine the exact amount and nature of these substances in different extracts of the plant.

\section{Declarations}

\section{Ethics Approval and Consent to Participate}

There is no involvement of human or animal in this study.

\section{Consent for Publication}

All other authors declare no conflict of interest.

\section{Availability of Data and Materials}

The authors confirm that the data supporting the findings of this study are available within the article.

\section{Competing Interests}

We declare that we have no significant competing financial, professional, or personal interests that might have influenced the performance or presentation of the work described in this manuscript.

\section{Funding}

This work was supported and funded scheme by Faculty of Pharmacy (grant no: 61103), Tabriz University of Medical Sciences.

\section{Authors' Contributions}

$\mathrm{MZ}$ and HF performed the experiments; MZ, ES, OM and PA analyzed of data; HF, and VT prepared the manuscript; PA and VT wrote and edited the manuscript; PA designed the experiments; PA led and supervised the project.

\section{Acknowledgements}

We would like to thank Dr. Baradaran for their supportive help in performing the anti-proliferative part.

\section{References}

1. Mousavi SM, Montazeri A, Mohagheghi MA, Jarrahi AM, Harirchi I, Najafi M, et al. Breast cancer in Iran: an epidemiological review. The breast journal. 2007;13(4):383-91

2. Zeinomar N, Knight JA, Genkinger JM, Phillips K-A, Daly MB, Milne RL, et al. Alcohol consumption, cigarette smoking, and familial breast cancer risk: findings from the Prospective Family Study Cohort (ProF-SC). Breast Cancer Research. 2019;21(1):1-14

3. Trichopoulos D, MacMahon B, Cole P. Menopause and breast cancer risk Journal of the National Cancer Institute. 1972;48(3):605-13.

4. Taraphdar AK, Roy M, Bhattacharya R. Natural products as inducers of apoptosis: Implication for cancer therapy and prevention. Current science. 2001:1387-96

5. Harvey AL. Natural products in drug discovery. Drug discovery today. 2008:13(19-20):894-901

6. Seyfi R, Kahaki FA, Ebrahimi T, Montazersaheb S, Eyvazi S, Babaeipour $\checkmark$, et al. Antimicrobial peptides (AMPs): roles, functions and mechanism of action. International Journal of Peptide Research and Therapeutics. 2020;26(3):1451-63.

7. Alipour M, Khanmohammadi O. Antibacterial activity of plant extracts against oral and skin pathogens. African Journal of Microbiology Research. 2011;5(19):2909-11.

8. Fulda S, Efferth T. Selected secondary plant metabolites for cancer therapy World Journal of Traditional Chinese Medicine. 2015:1(1):24

9. Mohammadzadeh F, Monirifar H, Saba J, Valizadeh M, Haghighi AR, Zanjani BM, et al. Genetic variation among Iranian alfalfa (Medicago sativa L.) populations based on RAPD markers. Bangladesh Journal of Plant Taxonomy. 2011:18(2):93-104.

10. Safarzadeh E, Shotorbani SS, Baradaran B. Herbal medicine as inducers of apoptosis in cancer treatment. Advanced pharmaceutical bulletin. 2014;4(Suppl 1):421.

11. Elujoba AA, Odeleye O, Ogunyemi C. Traditional medicine development for medical and dental primary health care delivery system in Africa.

African Journal of Traditional, Complementary and Alternative Medicines. 2005;2(1):46-61.

12. Maikhuri R, Nautiyal S, Rao K, Saxena K. Role of medicinal plants in the traditional health care system: a case study from Nanda Devi Biosphere Reserve. Current Science. 1998:152-7.

13. Jeong G-S, Kwon O-K, Park B-Y, Oh S-R, Ahn K-S, Chang M-J, et al. Lignans and coumarins from the roots of Anthriscus sylvestris and their increase of caspase-3 activity in HL-60 cells. Biological and Pharmaceutical Bulletin. 2007:30(7):1340-3.

14. Lee SH, Son MJ, Ju HK, Lin CX, Moon TC, Choi H-G, et al. Dual inhibition of cyclooxygenases-2 and 5-lipoxygenase by deoxypodophyllotoxin in mouse bone marrow-derived mast cells. Biological and Pharmaceutical Bulletin. 2004;27(6):786-8

15. Sudo K, Konno K, Shigeta S, Yokota T. Inhibitory effects of podophyllotoxin derivatives on herpes simplex virus replication. Antiviral Chemistry and Chemotherapy. 1998;9(3):263-7.

16. Lin CX, Lee E, Jin MH, Yook J, Quan Z, Ha K, et al. Deoxypodophyllotoxin (DPT) inhibits eosinophil recruitment into the airway and Th2 cytokine expression in an OVA-induced lung inflammation. Planta medica. 2006;72(09):786-91.

17. Kozawa M, Baba K, Matsuyama Y, Kido T, Sakai M, TAKEMOTO T. Components of the root of Anthriscus sylvestris HOFFM. II. Insecticidal activity. Chemical and Pharmaceutical Bulletin. 1982;30(8):2885-8.

18. Jin M, Moon TC, Quan Z, Lee E, Kim YK, Yang JH, et al. The naturally occurring flavolignan, deoxypodophyllotoxin, inhibits lipopolysaccharide-induced iNOS expression through the NF-KB activation in RAW264. 7 macrophage cells. Biological and Pharmaceutical Bulletin. 2008;31(7):1312-5.

19. Lin CX, Son MJ, Ju HK, Moon TC, Lee E, Kim SH, et al. Deoxypodophyllotoxin, a naturally occurring lignan, inhibits the passive cutaneous anaphylaxis reaction. Planta medica. 2004;70(05):474-6.

20. Kiso Y, Konno C, Hikino H, Yagi Y, Hashimoto I. Liver-protective actions of desoxypodophyllotoxin and its analogs. Journal of pharmacobio-dynamics. 1982;5(8):638-41 
21. Lee SK, Kim Y, Jin C, Lee SH, Kang MJ, Jeong TC, et al. Inhibitory effects of deoxypodophyllotoxin from Anthriscus sylvestris on human CYP2C9 and CYP3A4. Planta medica. 2010;76(07):701-4.

22. Choi H, Lee J, Shin H-J, Lee B-G, Chang I, Hwang J-S. Deoxypodophyllotoxin reduces skin pigmentation of brown guinea pigs. Planta medica. 2004; 70(04):378-80.

23. Chen H, Jiang H-Z, Li Y-C, Wei G-Q, Geng Y, Ma C-Y. Antitumor constituents from Anthriscus sylvestris (L.) Hoffm. Asian Pacific Journal of Cancer Prevention. 2014;15(6):2803-7.

24. Beheshtirouy S, Mirzaei F, Eyvazi S, Tarhriz V. Recent Advances on Therapeutic Peptides for Breast Cancer Treatment. Current Protein \& Peptide Science. 2020

25. Bray F, Ferlay J, Soerjomataram I, Siegel RL, Torre LA, Jemal A. Global cancer statistics 2018: GLOBOCAN estimates of incidence and mortality worldwide for 36 cancers in 185 countries. CA: a cancer journal for clinicians. 2018;68(6):394-424.

26. Asadi-Samani M, Kooti W, Aslani E, Shirzad H. A systematic review of Iran's medicinal plants with anticancer effects. Journal of evidence-based complementary \& alternative medicine. 2016;21(2):143-53.

27. Lai P, Rao H, Gao Y. Chemical composition, cytotoxic, antimicrobial and antioxidant activities of essential oil from Anthriscus caucalis M. Bieb grown in China. Records of Natural Products. 2018;12(3):290-4.

28. Yong Y, Shin SY, Lee YH, Lim Y. Antitumor activity of deoxypodophyllotoxin isolated from Anthriscus sylvestris: Induction of G2/M cell cycle arrest and caspase-dependent apoptosis. Bioorganic \& medicinal chemistry letters. 2009;19(15):4367-71.

29. Olaru OT, Nițulescu GM, Orțan A, Dinu-Pîrvu CE. Ethnomedicinal, phytochemical and pharmacological profile of Anthriscus sylvestris as an alternative source for anticancer lignans. Molecules. 2015;20(8):15003-22.
30. Jung $\mathrm{CH}$, Kim H, Ahn J, Jung SK, Um MY, Son K-H, et al. Anthricin isolated from Anthriscus sylvestris (L.) Hoffm. inhibits the growth of breast cancer cells by inhibiting Akt/mTOR signaling, and its apoptotic effects are enhanced by autophagy inhibition. Evidence-Based Complementary and Alternative Medicine. 2013;2013.

31. Harada H, Yamashita U, Kurihara H, Fukushi E, Kawabata J, Kamei Y. Antitumor activity of palmitic acid found as a selective cytotoxic substance in a marine red alga. Anticancer research. 2002;22(5):2587-90.

32. Kim SJ, Chung WS, Kim SS, Ko SG, Um JY. Antiinflammatory effect of Oldenlandia diffusa and its constituent, hentriacontane, through suppression of caspase-1 activation in mouse peritoneal macrophages. Phytotherapy Research. 2011;25(10):1537-46.

33. Yang J-H, Lee C-H, Monteiro-Riviere NA, Riviere JE, Tsang C-L, Chou C-C. Toxicity of jet fuel aliphatic and aromatic hydrocarbon mixtures on human epidermal keratinocytes: evaluation based on in vitro cytotoxicity and interleukin-8 release. Archives of toxicology. 2006;80(8):508-23.

34. Fukuzawa M, Yamaguchi R, Hide I, Chen Z, Hirai Y, Sugimoto A, et al. Possible involvement of long chain fatty acids in the spores of Ganoderma lucidum (Reishi Houshi) to its anti-tumor activity. Biological and Pharmaceutical Bulletin. 2008;31(10):1933-7.

35. Van Uden W, Bos JA, Boeke GM, Woerdenbag HJ, Pras N. The large-scale isolation of deoxypodophyllotoxin from rhizomes of Anthriscus sylvestris followed by its bioconversion into 5-methoxypodophyllotoxin $\beta$-Dglucoside by cell cultures of Linum flavum. Journal of Natural Products. 1997;60(4):401-3.

36. Lv M, Xu H. Recent advances in semisynthesis, biosynthesis, biological activities, mode of action, and structure-activity relationship of podophyllotoxins: an update (2008-2010). Mini reviews in medicinal chemistry. 2011;11(10):901-9. 